\title{
As práticas curriculares em Matemática que se produzem pelo governo do IDEB
}

\author{
Samuel Edmundo Lopez Bello*
}

\begin{abstract}
Resumo
Este texto analisa por que e de que maneira se mobilizam determinadas práticas curriculares no espaço escolar. Trata-se de mostrar como e por que se dá o Governo da instituição escolar pelos números do IDEB; quais estratégias se utilizam para a produção/mobilização dessas ações de governo. A partir do conceito de numeramentalização, de inspiração foucaultiana, é que se vê a operatividade do índice numa lógica sedutora da ciência como expressão de racionalidade e razão, a qual encontra no imperativo da contextualização do ensino a sua força impulsionadora. Sugere-se, por fim, uma postura ética na formação de professores que, de posse desta analítica, constitua uma singularidade das práticas curriculares como contraponto às ações de governo da política educacional.

Palavras-chave: Práticas curriculares - avaliação e desempenho em matemática - Educação Básica Governo dos números
\end{abstract}

\section{Curricula Practices of Mathematics and the government of IDEB}

\begin{abstract}
This text aims to analyze why and how certain practices are mobilized in the school curriculum. Our goal is to show how and why the government of the school by the numbers of IDEB, what strategies are those that are used for the production / mobilization of these government actions. From the concept of Foucauldian inspiration so-called "numeramentality", we can realize the operativity of the index in a seductive logic of science as an expression of rationality and reason, which takes the context of teaching as imperative of their driving force. We suggest an ethical stance in teacher education which, from our analitical point of view, institutes a singularity of curriculum practices as a counterpoint to the actions of government of education policy.

Keywords: Curricula Practices - Evaluation and Performance in mathematics - Schooling - Government by numbers
\end{abstract}

\section{Introdução}

Tem sido cada vez mais recorrente sentir a preocupação, nas diversas instâncias institucionais (Universidades, Escolas, Secretarias de Governo) e pelos mais diversos segmentos da sociedade (Pais de Família, professores, meios de comunicação), que o ensino na escola e o aproveitamento dos nossos estudantes não andam bem, em particular no ensino de Matemática. Esses dizeres ganham fôlego e encontram uma sustentação de caráter empírico-objetivo em índices que são produzidos para essa finalidade, a partir de avaliações em larga escala. Refiro-me, neste caso particular, ao IDEB - Índice de Desenvolvimento da Educação Básica, o qual tem se tornado um dos principais indicadores de como anda a "saúde" da Educação no Brasil. Como é sabido, os índices para 2012 foram calculados com base no desempenho dos estudantes em avaliações de português e matemática combinando-se com as taxas de aprovação, reprovação e abandono escolar. ${ }^{1}$

No caso da "realidade educacional revelada" por esses índices, a situação caracterizada para o Estado do Rio Grande do Sul tem sido considerada por diversos setores da opinião pública como preocupante: 5,1 para o IDEB ao final dos anos inicias; 3,8 para os anos finais do Ensino Fundamental e 3,4 para o IDEB Ensino Médio ${ }^{2}$.

Muitas críticas e ressalvas poderão ser feitas à maneira como este índice é construído, em particular, se considerarmos que:

Os resultados representam uma espécie de "fotografia" do momento, não revelando a complexidade do processo de aprendizagem, em razão da qual, embora seja um indicador importante, ele por si só não explica as reais condições de aquisição do conhecimento (RIO GRANDE DO SUL, SEDUC/RS). ${ }^{3}$

Sob a questão: Por que o mau desempenho dos jovens estudantes, em particular, na disciplina de Matemática? Ou, por que $89 \%$ chegam ao final do Ensino Médio sem aprender o esperado? Tem sido muito insistente a procura, por parte da Mídia, pelas causas da situação educacional para o estado do RS que evidenciam esses índices. Certamente, não podem ser igualados os sentidos atribuídos aos termos desempenho e aprendizado. Contudo, nós,

* Endereço eletrônico: samuel.bello@ufrgs.br 
professores universitários, temos uma percepção ainda que intuitiva, de que alguma coisa não está funcionando de modo adequado no processo de ensino-aprendizagem. Podemos, inclusive, dizer que cada vez mais alunos chegam ao ensino Superior sem saber mobilizar minimamente objetos matemáticos considerados básicos para "resolver" situações-problema que são propostas.

De modo geral, a mídia tem apontado como causa desse insucesso nos resultados obtidos pelo IDEB ao processo de Formação de professores, particularmente à formação pedagógica dos professores em exercício na rede pública de ensino, quando não referido situações mais sistêmicas como baixos salários e falta de infraestrutura. Em se tratando do Ensino Médio, a essas causas poderiam se agregar a evasão escolar e a infrequência às aulas por parte dos estudantes, as quais, até alguns anos, eram facilmente "naturalizadas" ao olhar de professores e das equipes diretivas nas diferentes escolas públicas estaduais da cidade de Porto Alegre, ao serem visitadas quando da realização dos trabalhos de orientação nas disciplinas de Prática de Ensino do Curso de Licenciatura em Matemática da UFRGS $^{4}$.

No entanto, quando Poder público, Pesquisadores, Profissionais do Centros de Formação Universitária são desafiados e tensionados a oferecer respostas, os encaminhamentos podem ser outros. Poder-se-ia dizer que os problemas da Educação Básica, em geral, não respondem apenas às questões da gestão escolar, mas há uma responsabilização dos resultados no Ensino Médio a partir dos processos de ensino-aprendizagem que ocorrem no Ensino Fundamental, nos anos iniciais e, antes ainda, na educação Infantil.

De modo geral, para as autoridades e profissionais da educação, o problema da falta de interesse e da indisciplina na escola Básica, quando não se vincula diretamente às "lacunas" na formação acadêmica dos estudantes, é porque ora o professor não vincula o conteúdo matemático às aplicações ou problemas do dia-adia, ou porque a escola não investe em práticas de culturização escolar. Sobre este ultimo aspecto, Xavier $(2008$, p. 21) nos lembra que a categoria aluno é uma categoria cultural e precisa ser produzida pela escola contemporânea; posturas devem ser ensinadas através de procedimentos que componham as rotinas escolares. Da mesma forma, "as áreas de conhecimento precisam ser vistas como instrumentos para autoconhecimento, conhecimento do outro, conhecimento do mundo social e natural" (idem, ibidem, p. 27).
Do meu lugar de pesquisador e como professor do Programa de Pós-graduação em Educação da Universidade Federal do Rio Grande do Sul, vinculado à linha de pesquisa das filosofias da diferença, em meio a todas essas possíveis causas do baixo desempenho, sinto-me desafiado a (re)tomar a questão pelo lado da análise curricular. Nesse sentido, tomarei o Currículo como foco de experiência, no sentido foucaultiano, isto é, como ponto de inflexão no qual se articulam e se sobrepõem, primeiro, as formas de saber possível, segundo, as matrizes normativas de comportamento para os indivíduos; para posteriormente se constituírem os modos de existência virtuais para sujeitos possíveis de um determinado tempo histórico (FOUCAULT, 2010, p. 4).

Para tanto, deve-se tomar o Currículo como objeto de pensamento e de reflexão; pesquisá-lo, revisitá-lo, desconstruí-lo, reinventálo, em outras palavras, tornar o Currículo um acontecimento na pesquisa em Educação. Nesse sentido, Corazza (2004, p. 10) lembra-nos que pesquisar não quer dizer ultrapassar uma situação de desconhecimento, superar uma condição de ignorância ou uma passagem de um saber a um não saber. Fazer do currículo um acontecimento na pesquisa significa fazer "o choque com o já feito, uma experimentação dos conceitos e das imagens do pensamento que animam uma Pesquisa do acontecimento" (idem, ibidem, p. 11); suspender os modos de pensar consagrados pela instituição escolar; desarmar os modelos que prescrevem as formas em que acontece ou não o aprendizado, os princípios sobre os quais se sustenta a seleção de conteúdos, o que se consideram aprendizagens significativas, entre outros.

Assim, esse pensar curricular não se refere a uma reestruturação ou (re)acomodação dos conteúdos escolares considerados esperados, e sim a uma uma analítica sobre por que e de que maneira se mobilizam determinadas práticas curriculares no espaço escolar, como se constituem os saberes que as compõem; mostrar como e por que se dá o Governo da instituição escolar pelos números do IDEB; que estratégias são aquelas que se utilizam para a produção/mobilização dessas ações de governo; como atuam os princípios que orientam e constituem as práticas curriculares com vistas à melhoria da melhoria da qualidade de ensino. É disto que trata este artigo.

\section{Do Governo das práticas curriculares escolares pelo IDEB}


O que impacta na reformulação de um currículo? Alunos de graduação, professores em exercício na educação básica consideram que as disciplinas escolares, em particular a Matemática, são mais ou menos as mesmas há muito tempo, dada a tradição com que tem se apresentado o seu ensino. No entanto, segundo Santos L. (1994), uma análise cuidadosa nos revela que há uma variação na forma e no conteúdo, isto é, nas formas metodológicas a serem privilegiadas no processo de ensino-aprendizagem quanto à própria seleção de conteúdos. Para a autora, a literatura mostra que na análise de tais mudanças podem ser encontrados fatores diretamente ligados ao contexto social (eventos sociais, políticos e de natureza intelectual-cultural). Da mesma forma, é importante destacar que questões relacionadas à realização de políticas curriculares envolvem poder, controle, coalisões, negociações e compromissos entre grupos e indivíduos operando dentro e fora do sistema escolar.

Da mesma forma a pesquisadora sustenta que: "em decorrência disto, é importante verificar quais são as propostas de ensino na área, envolvendo conteúdo e método, bem como os eventos que estariam propiciando a hegemonia de determinada tendência em períodos e locais definidos." (idem, ibidem, pp. 159-160). Dessa forma, a história das matérias ou disciplinas escolares deve abranger não apenas os conhecimentos incluídos em um curso de estudo, mas também os excluídos, devendo ainda analisarem-se os efeitos sociais dessa inclusão ou exclusão.

Entre as causas apontadas por Santos (1994) que influenciariam a organização curricular, além dos estudos advindos da psicologia do desenvolvimento, do controle assumido por especialistas da comunicação pela elaboração dos livros didáticos e os vestibulares, aponta autora, deve se dar especial atenção aos exames nacionais e a relação dos mesmos com as políticas e os movimentos internacionais.

Tomar-se-á como ponto de partida esse último aspecto apontado por Santos, isto é, o dos Exames Nacionais e sua relação com os movimentos internacionais, para tratar daquilo referente ao "Governo da escola e das práticas curriculares pelos números" para seguidamente mostrar como o currículo, nessa ação de governo; ou melhor, as práticas curriculares ${ }^{5}$ escolares em matemática sofrem impactos a partir do que denominaremos de "A Curricularização dos descritores da avaliação".

Para Sousa (2003) não se pode falar de impactos de políticas de avaliação sem levar em consideração o procedimento ou processo que é tomado como referência. No caso da Educação básica brasileira, o IDEB - índice de desenvolvimento da educação Básica - assume centralidade na política educacional do país, visto que apontaria ao alcance dos objetivos de uma melhoria da eficiência e da qualidade da Educação. E pelos termos eficiência e melhoria Sousa (idem, p. 177) expressa:

Melhoria da eficiência refere-se ao fluxo
escolar (taxas de conclusão, de evasão, de
repetência, estimulando-se por exemplo, a
implantação da progressão continuada,
classes de aceleração, organização
curricular em ciclos) [...] Quanto à
concepção de qualidade do ensino
adotada, será possível sua explicitação
[...] sob o pressuposto de se dar
visibilidade e controle público aos
produtos ou resultados educacionais,
disponibilizando aos usuários elementos
para escolha dos serviços ou para
pressão sobre as instituiçóes ofertantes.

Porém, cabe perguntar: por que o IDEB impactaria tanto nas práticas curriculares de professores e escolas em Matemática?

Em princípio, poder-se-ia dizer que isso ocorre porque o índice tem como parâmetro o rendimento dos alunos na Prova Brasil nas disciplinas de Língua Portuguesa e Matemática, combinando-se com indicadores de fluxo como taxas de promoção, repetência, evasão, calculados a partir do Censo Escolar ${ }^{6}$. Do ponto de vista das mobilizações produzidas, estudos empíricos como os desenvolvidos por LIMA e SILVA-NETO (2010) mostram que no momento da divulgação dos resultados do IDEB, os mesmos são assunto de reuniões, conversas e indagações, entre professores de Matemática, principalmente no sentido de se decidir o que fazer para se atingirem as metas em anos seguintes.

Por enquanto, se a proposta é entender o porquê e como um índice propicia toda uma possibilidade de mobilizar uma série de condutas e procedimentos quanto à melhoria da eficiência da Educação e do desempenho escolares, a questão do poder parece ser central nessa discussão. Segundo Foucault (1988), é pela compreensão relacional do poder-saber e das formas de Governo (FOUCAULT, 2008a), ou, como nos sugere Veiga-neto (2005) Governamento $^{7}$, que se abre a possibilidade de compreender artes, racionalidades, saberes, regimes específicos de formas de pensar e agir envolvidos na produção de práticas e tecnologias, para a produção de condutas em si mesmo e nos 
outros. Essa definição de governo como condução da conduta é importante para se entender o funcionamento, controle ou direcionamento de comportamentos e atitudes dentro de instituições ou comunidades, na alteridade e na relação consigo mesmo. É importante destacar que, no entendimento relacional que Michel Foucault faz do poder-saber, que utiliza o termo governamentalidade (FOUCAULT, 2008b) para se referir à disposição, organização, distribuição, estudo, análise de práticas, racionalidades e técnicas de governamento ${ }^{8}$ e na produção de práticas e tecnologias específicas, ora no que se refere à relação entre as tecnologias de governamento dos outros (populações) e as tecnologias próprias de governamento de si (indivíduos). Gordon (1991) e Rose (1997), bem como o próprio Foucault (idem), discutiram como o liberalismo e o neoliberalismo se constituíram contemporaneamente como racionalidades políticas, princípios racionais de ação para a orientação das condutas, dos modos de ser e de agir. Nesse sentido, e tomando como referência a noção foucaultiana de Governamentalidade (Foucault, 2008a) e fazendo o embaralhamento de suas possibilidades (processos de governo, racionalidade, práticas, tecnologias), é que utilizar-se-á a "Numeramentalidade" (Bello, $2011)^{9}$. Essa noção é uma entre tantas outras perspectivas analíticas para o estudo de normatividades produtoras, orientadoras e reguladoras de condutas, modos de pensar e agir na contemporaneidade baseadas fortemente na quantificação, na medição, no uso e registro de números. A noção Foucaultiana de Governamentalidade e/ou governamento, e aquilo que ele denomina de "processos de governamentalização" das artes e técnicas de governar, serviu-me de base à invenção do neologismo Numeramentalidade, em português, que poderia ser melhor expresso como: Numeramentalité, em francês, em analogia ao termo Gouvernementalité, próprio da teorização Foucaultiana $^{10}$.

Essa noção - a de Numeramentalidade, ora também referida em vários momentos como numeramentalização - será entendida como "a combinação entre as artes de governar e as práticas e as normatividades em torno do numerar, do medir, do contabilizar, do seriar, as quais orientam a produção enunciativa das práticas sociais, em âmbitos institucionais - como o da escola, por exemplo - e nos planos de agenciamentos comportamentais contemporâneos - como nos do currículo. Esses agenciamentos tendem posicionar a Numeramentalidade não apenas como um dispositivo, como referido por
Foucault, mas como um processo, no qual se operam práticas, constituem-se discursos e identidades, regulam-se condutas, incitando-se, sempre que possível, a processos de subjetivação.

Neste caso, tanto a ferramenta metodológica e conceitual da Governamentalidade como a numeramentalização são aqui consideradas não apenas como dispositivos de uma época, modos e formas de se expressar uma racionalidade de governo; elas são ferramentas para se entender a produção de tecnologias de governamento das instituições e da gestão (escolas, práticas curriculares) com impactos na tomada de decisão de caráter político. Governamentalidade e Numeramentalização são conceitos que operam como grades analíticas que auxiliam no entendimento da produtividade e da centralidade das quantidades, dos números (medições, índices, taxas), seus registros e usos como expressão da verdade nos modos de pensar e se conduzir dos indivíduos de uma sociedade.

$\mathrm{Se}$ entendermos como tecnologia de governamento aqueles meios a que, em determinada época, autoridades de tipo diverso utilizam para moldar, instrumentalizar e normalizar as condutas de indivíduos e também parcelas da população, então a estatística ${ }^{11}$, por exemplo, pode ser considerada uma tecnologia para governar (Traversini e Bello, 2009, p. 143), principalmente se a mesma serve normativamente para o controle e a regulação de riscos sociais:

A estatística pode ser entendida como um meio, composto por saberes e por procedimentos técnicos específicos que é utilizada por governos das diferentes esferas públicas, para situar comunidades [...] como sendo de risco social. Analisar como se conduz a conduta desse conjunto de indivíduos para sair da condição de analfabetismo [por exemplo] é tomar a prática da gestão do risco como uma forma de governar que necessita do saber estatístico para tomar decisões (TRAVERSINI e BELLO, 2009, p. 143).

Segundo Popkewitz e Lindblad (2001, p 114), as estatísticas cumprem uma função prática na governança educacional moderna. Isto porque as estatísticas participam da lógica sedutora da ciência num momento histórico de racionalidade e razão. Segundo os autores, muitas das relações entre governança, ações sociais e efeitos educacionais em relação a inclusão social são estatísticas. "A informação aparece como dados que convidam a comparações entre categorias no tempo e no espaço e podem ser utilizados em 
vários tipos de análises quantitativas, mais particularmente quando a pesquisa lida com política educacional" (idem, ibidem, p. 114).

O IDEB, para o caso da política educacional brasileira, pode ser visto como um exemplo disso. Em princípio porque o conceito de comparação é constituinte do índice como produto estatístico, as próprias medidas obtidas a partir dos dados estatísticos são resultados de comparação com unidades ou sistemas-padrão consideradas desejáveis. Segundo Sousa (2003), a avaliação realizada na produção dos dados que comporão o IDEB predispõe a: uma ênfase nos produtos e resultados; uma atribuição de mérito tornando-se o mesmo individual para instituições e alunos; uma classificação de desempenhos escalonados; uma comparação a padrões externos não articuladas à auto-avaliação ${ }^{12}$. Vê-se também que o trabalho desenvolvido por Lima e Silvaneto (2010) conduziu a uma busca pela relação entre o resultado da avaliação expressa pelo índice com as condições socioeconômicas dos estudantes e suas concepções sobre matemática. $O$ índice não apenas orienta políticas, mas também pesquisas.

Dessa maneira, o índice torna-se propulsor de condutas e encaminhamentos a serem adotados pelas escolas, cabendo ao Estado um papel mais regulador, avaliador, fiscalizador, do que propositor.

Diferente do que foi argumentado em Traversini e Bello (2009, p. 147), a figura do professor, nesse contexto, adquire centralidade tanto quanto os índices, visto que o esforço do professor estará em relação direta com o aumento do indicador. No dizer de Popkewitz e Lindbland (2001, p. 116-117), os indicadores educacionais tornam-se "a linguagem que atravessa as declarações do Estado, dos profissionais e das fundações sobre os professores e suas práticas educacionais $[\ldots]$ nada é mais poderoso, para influenciar os ganhos de realização dos alunos, que a qualidade do professor". Da mesma forma, continua o autor, esses indicadores também definem o problema das mudanças educacionais em relação a números: números de professores não licenciados, números de professores ensinando na área de formação, porcentagem de variância entre realização e experiência do professor, e assim por diante. Portanto, conclui, começamos nossa discussão sobre estatísticas com uma observação a respeito das funções práticas dos números; eles intervêm nos processos de governo, uma vez que moldam nossa maneira de ver as possibilidades de ação, de inovação e até a nossa visão de nós mesmos. A produção de estatísticas oficiais é, hoje, "um empreendimento rotineiro que tem uma ampla infraestrutura em programas de Estados e de Universidade cuja escala e sofisticação se estende a campos mais vastos da vida social e que se infiltra profundamente no funcionamento da sociedade" (Starr, apud POPKEWITZ e LINDBLAND, 2001, p. 117).

\section{Os efeitos da Curricularização dos descritores da avaliação}

A relação poder-saber ora constituída, poder para produzir condutas - saberes/índices estatísticos (como objetivação de uma condição, expressão de uma verdade) - incide sobre os viventes $^{13}$, tornando-os indivíduos para uma determinada realidade histórica e social. Como modeladores de conduta, as estatísticas não são apenas meros sistemas lógicos, mas um campo de práticas culturais que normaliza, individualiza, divide. Os números governam não como números em si, mas pela possibilidade que oferecem de entrecruzar discursos outros que circulam traçando perfis e inventariando/inventando individualidades - daí o caráter tecnológico dos índices estatísticos como o IDEB. Ao mesmo tempo em que o uso de estatísticas é uma maneira de construir classes humanas para abrir possibilidades para o futuro, é também um modo para que a individualidade seja descrita de novo e que as pessoas possam experimentar a si mesmas. Criar novas maneiras de classificar as pessoas é também mudar a maneira do que podemos pensar de nós mesmos, mudar nosso sentido de valor próprio e, inclusive, mudar os modos de significar nossas próprias experiências (POPKEWITZ e LINDBLAND, 2001).

Em Bello e Traversini (2011), ao discutirmos a inserção curricular do saber estatístico no contexto dos PCN (Parâmetros Curriculares Nacionais), consideramos que essa Curricularização atendia muito mais a objetivos políticos no que se refere à formação de um tipo específico de sujeito/indivíduo aluno, do que propriamente a preocupações epistêmicas.

Ao curricularizarem o saber estatístico, os PCN trazem para si a expectativa de formação de um determinado tipo de sujeito que tome esse saber $e$, consequentemente, a matemática numa dimensão instrumental como auxílio para suas atividades [...] A conduta esperada, a nosso ver, consiste no aluno saber decidir, ter iniciativa e segurança para utilizar os conhecimentos no momento oportuno. Os conteúdos aprendidos têm efeitos, e, na racionalidade neoliberal 
vigente, o pressuposto é que o aluno seja capaz de posicionar-se como um sujeito produtivo, a partir das diferentes situações relacionadas à sua vida (Idem, ibidem, p. 866-867).

Nesse sentido - e considerando o currículo não apenas uma seleção de conteúdos, mas o conjunto de experiências que a escola dispõe para as aprendizagens escolares -, entender os descritores em Matemática - organizadores das matrizes de referência para a Prova Brasil/SAEB e o $\mathrm{ENEM}^{14}$ - como saberes normativos das práticas curriculares de professores de Matemática e em resposta aos problemas de ensino-aprendizagem supostamente revelados pelos índices do IDEB implica também significar os comportamentos docentes em termos de "boas" formas de serprofessor.

Seguindo os rastos de Miguel et al (2008) e Miguel (2010), em Bello (2010), Pinho e Bello (2011) e recentemente em Bello (2012), temos mostrado que uma concepção normativa de "saber" nos possibilitaria investigar também como os sujeitos operam e se constituem seguindo regras de práticas sociais distintas. $\mathrm{O}$ entendimento do que seria seguir uma regra para discutirmos as práticas curriculares escolares matemáticas, poria "em suspenso" as teorizações construtivistas ou socioculturais do saber matemático, que localizam nos objetos (pela via da experimentação), nos sujeitos (pela via da abstração) ou nas relações sociais (por um viés sócio-histórico-cultural), a "construção" dos ditos conhecimentos matemáticos, bem como o convencimento sobre quais as ações que devem ser realizadas para que isso ocorra. Desse modo, as práticas curriculares, como práticas sociais regradas, no âmbito institucional da escola, conduzem-nos para um sentido normativo do próprio fazer matemático forjado por linguagens que não estão em um plano ideal ou funcionam como uma irredutível máquina lógica (como na visão platônica), mas encontram suas explicações e razões de sua existência em suas próprias ações. A referência sobre o que é seguir as regras desse fazer matemático é dada pelas suas próprias práticas e não fora delas.

Não me deterei na analítica da linguagem que organiza as práticas curriculares matemáticas e nem na enumeração enunciativa de cada um dos descritores. O objetivo é mostrar como eles, ao mesmo tempo que são parâmetros de avaliação, tornam-se conteúdos escolares e constituintes normativos das práticas curriculares escolares em termos de condutas que deverão ser produzidas. Afinal, espera-se que, a partir do IDEB e da média obtida por cada escola na sua avaliação, procedase a uma análise por parte das escolas e professores, principalmente identificando-se as habilidades já conquistadas, as que estão em processo de construção e aquelas que precisam ser retomadas e trabalhadas pedagogicamente. Para isso,

é preciso identificar e descrever itens acertados pelos alunos com nota no ponto que se quer interpretar. Só com a construção e a disseminação desse tipo de interpretação pedagógica, a Prova Brasil poderá influenciar mais decisivamente o ensino (BRASIL, 2010, p. 8).

Em consonância com os PCN e PCNEM, os descritores da matriz de Matemática se inserem na perspectiva de um ensino-aprendizagem de qualidade sustentados principalmente no desenvolvimento de competências e habilidades necessários para o convívio social, inserção e participação do/no espaço público. Ainda sob os pressupostos da psicologia cognitiva, espera-se que o aluno alcance determinados níveis de abstração para compreender o conhecimento científico que o ajudariam nessa tarefa. A expectativa que se sobrepõe a qualquer justificativa do porquê este ou aquele descritor é de ordem epistêmica. Assim, reconhecer ${ }^{15}$ e identificar $^{16}$ são verbos muito recorrentes nos descritores para vincular as ações didáticas a conceitos e procedimentos como tradicionalmente trabalhados na instituição escolar.

Contudo, melhores resultados nas avaliações, na esteira da política pública educacional, são traduzidas como melhorias de desempenho não apenas dos alunos, mas da qualidade das práticas pedagógicas que realizam professores, instituições - escolas e universidades - e sistema como um todo. Nesse sentido, tomar, por exemplo, comentários, sugestões de trabalho evidenciados nos documentos oficiais das Matrizes de Referência ou, até mesmo, questões propostas nas provas sobre os temas matemáticos e seus descritores - seja para o Ensino Fundamental ou Ensino Médio - como normativas para as práticas curriculares pode significar um melhor desempenho nas avaliações. Considerando o que dizem TRAVERSINI e BELLO, 2009, (p. 147) tomar os indicadores como normativos constituintes de uma prática curricular e ensinar os estudantes a ter um bom desempenho nas provas poderia ser uma possibilidade de confronto frente aos objetivos educacionais expressos numa política de avaliação nacional. Confronto esse que assume a forma contemporânea de investimento, 
visto existem politicas publicas que redistribuem os recursos conforme a melhoria dos indicadores. Entretanto, o sistema em conexão com a sua racionalidade governamental neoliberal quer mais. Sob a consigna de resolver problemas, espera mudanças no tipo de respostas dadas pelos alunos, bem como nos encaminhamentos curriculares feitos pelos professores.

Utilizando-se este ou aquele conteúdo com fins prático-aplicativos, deseja-se por parte do aluno uma "compreensão do que está sendo ensinado e, muitas vezes, de sua aplicação no cotidiano, [para tanto] é preciso utilizar um tipo de linguagem acessível e, também, delimitar o nível de complexidade do conhecimento que será abordado pelo professor (BELLO e TRAVERSINI, 2011, p. 864 [grifo nosso]). Para Ribeiro e Lise (2010, p. 334 - 335) os descritores das Matrizes de referencia em consonância com os PCN procuram

"reconectar os diferentes blocos de conteúdos, ligar a Matemática com as situações cotidianas e as outras áreas de conhecimento; [...] o gosto pela matemática, o incentivo à pesquisa, desenvolvendo no aluno uma atitude investigativa diante das situaçõesproblema proposta em sala de aula, são alguns exemplo dessa compreensão mais ampla do que é ensinar e aprender Matemática segundo os PCNs.

Nessa esteira das situações-problema e da aplicabilidade de conhecimentos, vemos os saberes ligados à contextualização do ensino constituirem-se como imperativo de boas práticas pedagógicas, consequentemente da fabricação de certas identidades-aluno, bem como de identidades "bons - professores" de Matemática.

As críticas à contextualização e ao uso da realidade para o ensino de matemática não são recentes. Trabalhos como os de Bampi (1999), Santos C, (2008) e Knijnik et al (2006) e Santos S. (2009) e, de um modo mais amplo, em se tratando da Interdisciplinaridade, os trabalhos de Veiga-Neto $(1995,1997)$ questionam, sob um viés analítico pós-estruturalista, que esses temas estão longe de se constituírem em remédios ou soluções para os problemas do ensino. Essa seria apenas uma política de verdade da Educação Matemática, na teia do poder-saber, para se produzirem determinados tipos de identidades-sujeito (BELLO, 2010). Sujeito aqui entendido não como aquele que do ponto de vista cognitivo apreende conhecimentos, mas como aquele que se assujeita, se governa, se gerencia, se analisa, se julga, em último caso, produz-se, segundo as relações que estabelece com as verdades do seu tempo. Se os saberes estatísticos, por exemplo, desenham e regulam os sujeitos produtivos, criativos, que buscam segurança, que se responsabilizam por si mesmos (BELLO e TRAVERSINI, 2011, p. 867); da mesma forma, vemos a contextualização tornar-se um imperativo para a constituição do EU - sujeito - bom professor, o qual produz boas práticas curriculares, visto que essa contextualização opera - para além da teoria e da cientificidade da produção acadêmica em Educação Matemática como regra de conduta.

$\mathrm{O}$ que se quer dizer com isso é que a contextualização mobiliza e produz a busca pela sua objetivação, sua realização não pela cientificidade que a produziu, mas pela moralidade que lhe dá sustentação. Se se entende por moral um conjunto de valores e regras de ação propostas aos indivíduos e às comunidades por intermédio de aparelhos prescritivos diversos como podem ser as instituições educativas, as associações científicas, instancias públicas de gestão -, observa-se um dizer da educação matemática prescrevendo a contextualização do ensino como regra constituinte das práticas escolares. Se por moral entende-se a avaliação e medição das nossas ações pelo código prescrito, ter-se-á, pois, a contextualização como regra ou princípio de conduta desejável à constituição do bom professor. Aquele que quiser ser visto como bom professor contextualizará e incitará seu colega a fazê-lo. Afinal, a conjuntura normativa, que opera como verdade, captura esse seu sentido desde os tempos do platonismo na aproximação do homem ao que possa existir de mais puro, inteligível, virtuoso, justo.

É importante destacar que esses aspectos morais são propostos e sustentados desde o engendramento da modernidade como maneiras de se dirigir não apenas a finitude do homem, sua humanização por meio da razão, mas também para que se produza o estatuto metafísico da verdade e das regras constituintes das boas ações do agir dos indivíduos acima de seus contextos e finalidades. Nessa moral moderna, da qual está muito impregnada a escola, as boas razões para agir devem valer para todos os sujeitos escolares; por isso a moralidade possui um caráter normativo: trata-se de uma lei válida para todos na exata medida da sua racionalidade.

Contextualizar passa assim a ser entendido como um dever que gerará obrigação de uma determinada conduta escolar e uma culpa caso não se atinjam as finalidades educacionais, já que, o que parece, não realizamos nossa tarefa de 
bons professores - e o IDEB está ai para revelar essa nossa falta ao dever ${ }^{17}$. A contextualização opera nessa linha de pensamento: um dever que conjugado a outras boas ações produzirá práticas pedagógicas de sucesso. Assim, tornar a contextualização um imperativo significa dotá-la de uma unidade e de um caráter verdadeiro constituinte de toda prática curricular.

\section{Algumas considerações}

Até o momento verificou-se que, mesmo sendo ainda muito tímidas as teorizações em torno da noção de Numeramentalização, a partir da noção foucaultiana de Governamentalidade, a ferramenta analítica proposta mostra-se bastante produtiva para se discutir o caráter normativo dos saberes em torno dos índices de desempenho para se governar e se conduzir as condutas dos sujeitos escolares, como uma questão de verdade que orienta modos de pensar e agir pelas práticas curriculares que institui e as posições identitárias que produz.

Ao se trabalhar com a numeramentalização como conceito, extrapola-se o âmbito da Educação matemática, uma vez que se amplia a discussão da operatividade discursiva das formas e modos de subjetivação individuais e coletivos por diferentes espaços socialmente institucionalizados. Assim, não falamos de uma educação disciplinada ou disciplinar, mas de uma educação que diz respeito à produção de imperativos tomados mais como compromissos constitutivos de práticas e de individualidades num determinado momento histórico.

A analítica em torno do IDEB, como índice contemporâneo de produção de conduta, mostra-se mais como um compromisso moral e político do que epistemológico. E nesse sentido a resposta a ser dada deverá circular antes pelo plano da ética, para não se assumirem os descritores como constituintes de currículo, mas como ponto de partida para as ressignificações das práticas curriculares. A reflexão em termos éticos não deverá desconsiderar o caráter científiconormativo dos discursos, nem os valores contemporâneos sobre o que se consideram boas práticas pedagógicas, boas práticas de ensinoaprendizagem. A ética, como sugerida por Foucault (2007, 2009), refere-se à constituição de si mesmo como sujeito moral na sua relação com o outro; isso então poderia ser lido, em se tratando da nossa discussão sobre a constituição normativa de identidades escolares e de práticas curriculares, como a maneira de ser e de conduzir-se singularmente como professores. $\mathrm{E}$ isso deve ter também impactos na formação.
Como enunciamos no início deste trabalho, tomar o currículo ou as práticas curriculares como foco de experiência quer dizer conhecer as formas de saber construídas e constituídas, para o próprio currículo e suas práticas; para a educação; para a pedagogia; para a escola. Da mesma forma, conhecer as matrizes normativas prescritas para as formas de comportamento possíveis no espaço institucional escolar, sua gestão, seus princípios, suas estratégias, suas tecnologias de governo, sua disciplina, seu ordenamento. Nesse sentido, a formação teórico-acadêmica é importante, mas insuficiente para se fazer frente aos desafios que na contemporaneidade se oferecem no espaço institucional escolar. Não se podem ignorar os estudos do currículo e de suas práticas construídas pela história dos educadores. Porém, como nos lembra Corazza (2002, p.111-112), ao falar do que denomina de um currículo da diferença:

A ética de nossa ação educacional [...] está aliançada com culturas e políticas de muitos mundos, grupos, racionalidades, línguas, inteligências, grandezas, sensibilidades, histórias, realidades. Pluraliza nossas ações, ideias, palavras, relações, sujeitos, ver e ser visto, dizer $e$ ser dito, representar e ser representado. Coloca-nos no fluxo de educar todos os que vêm se reinventando, os que estão em metamorfose, os não-idênticos [...] Estimula diferentes formas de formular $e$ de viver práticas educacionais alternativas ao projeto neoliberal $e$ positiva meios de divulgar tais práticas, fazê-las circular e serem debatidas, de maneira a inspirar outras tantas.

Uma prática curricular contemporânea deverá agir inventando e reinventando sujeitos escolares com base em temáticas culturais que rejeitem estrategicamente currículos, provas, avaliações, desempenhos para todos e cada um.

\section{Referências Bibliográficas}

BAMPI, L. Efeitos de poder e verdade do discurso da Educação Matemática. Educação e Realidade. Porto Alegre, v. 24, n. 1, p. 115-143, jan./jun. 1999.

BELLO, Samuel E. L. Numeramentality: A research program in Mathematics Education. In: CIEAEM 63, 2011. Barcelona, Spain: 
Proceedings - Quaderni di Ricerca in Didattica (Mathematics). Palermo Italia, 2012 n. 22, Sup. 1, (jul. 2012), p. 114-117

Numeramentalização: o estudo das práticas e do governamento em Educação (e) Matemática na contemporaneidade. Reflexão e ação, Santa Cruz do Sul/RS, v. 20, n 2, 2012. 27 f. (no prelo).

- Jogos de Linguagem, Práticas discursivas e produção de verdade: contribuições para a Educação (matemática) contemporânea. Zetetiké, Campinas: FE/UNICAMP; Campinas: FE/UNICAMP, v. 18, Número temático, p. 545$588,2010$.

BELLO, Samuel Edmundo López; TRAVERSINI, Clarice Salete. Saber estatístico e sua curricularização para o governamento de todos e de cada um. Bolema, Rio Claro: IGCE/UNESP; Rio Claro: IGCE/UNESP, v. 24, n. 40, Edição Temática: Educação Estatística, p. 855-871, dez. 2011.

BRASIL. Ministério da Educação. PDE: Plano de Desenvolvimento da Educação: SAEB: ensino médio: matrizes de referência, tópicos e descritores. Brasília: MEC, SEB; Inep, 2008.127 p. : il.

CORAZZA, Sandra. Pesquisar o acontecimento: estudo em XII exemplos. In: TADEU, Tomaz; CORAZZA, Sandra; ZORDAN, Paola. Linhas de escrita. Belo Horizonte: Autêntica, 2004, p. 7-78.

Diferença pura de um pós-currículo. In:

LOPES A.; MACEDO, E. (org.) Currículo: debates contemporâneos. São Paulo: Cortez, 2002. p. 103-114.

FOUCAULT, Michel. Da Governamentalidade. In: FOUCAULT, Michel. Microfísica do Poder. Organização e tradução de Roberto Machado. 7. ed. Rio de Janeiro: Graal, 1988. p. 277-295.

O sujeito e o poder. In: DREYFUS, Humbert; RABINOW, Paul. Michel Foucault, uma trajetória filosófica: para além do estruturalismo e da hermenêutica. Rio de Janeiro: Forense Universitária, 1995. p. 231-249.

História da sexualidade 2: $\mathrm{O}$ uso dos prazeres. $12^{\mathrm{a}}$ ed. Rio de Janeiro: Edições Graal, 2007.
Segurança, território e população. São Paulo: Martins Fontes, 2008a.

. Nascimento da Biopolítica. São Paulo: Martins Fontes, 2008b.

. História da sexualidade 3: O cuidado de si. $10^{\mathrm{a}}$ reimpressão. Rio de Janeiro: Edições Graal, 2009.

O governo de si e dos outros. São Paulo: WMF Martins Fontes, 2010.

GORDON, Colin. Governmental rationality: an introduction. In: BURCHEL, G.; GORDON, C.; MILLER, P. (Ed.) The Foucault effect: studies in governmentality. Chicago: The University of Chicago, 1991. p. 1- 51.

KNIJNIK, G.; WANDERER, F. "A vida deles é uma matemática": regimes de verdade sobre a educação matemática de adultos no campo. Educação UNISINOS, v. 10, n. 1, jan./abr. 2006. São Leopoldo: UNISINOS.

LIMA, Arenilton de A.; SILVA NETO, João F. da. Avaliação em Matemática: uma análise do IDEB da Escola Estadual Antônia Macedo, Palmeira dos Indios - Alagoas. In: Anais do V Encontro de Pesquisa em Educação de Alagoas, PPGE - UFAL, 31/08 - 03/09 de 2010. $11 \mathrm{f}$.

MIGUEL, A. Percursos Indisciplinares na Atividade de Pesquisa em História (da Educação Matemática): entre jogos discursivos como práticas e práticas como jogos discursivos. In: Bolema. Rio Claro (SP), v. 23, no 35A, p. 1 a 57, abril 2010 .

MIGUEL, A.; VILELA, D. S. Práticas escolares de mobilização de cultura matemática. In: Cadernos Cedes, Campinas, v. 28, n. 74, p. 97120, jan./abr. 2008.

MIGUEL, Antônio; VILELA, Denise S.; MOURA, Anna R. L. Descontruindo a matemática escolar sob uma perspectiva pósmetafísica de educação. Zetetiké, Campinas: FE/UNICAMP; Campinas: FE/UNICAMP, v. 18, Edição especial, p. 123-195. 2010.

PINHO, Patrícia Moura; BELLO, Samuel Edmundo López. Práticas Matemáticas escolares como atividades regradas: modos de significar e se conduzir. In: Conferência Interamericana de Educação Matemática, 13, 2011, Recife. Anais 
da XIII Conferência Interamericana de Educação Matemática (XIII CIAEM). Recife: 26-30, jun. 2011. 12 fl. Disponível em:

<http://www.cimm.ucr.ac.cr/ocs/index.php/xiii_ci aem/xiii ciaem/paper/viewFile/2265/548> Acesso em: 15 ago. 2012 .

POPKEWITZ, T.; LINDBLAD, S. Estatísticas educacionais como um sistema de razão: relações entre governo da educação e inclusão e exclusão sociais. Educação e Sociedade, São Paulo, ano XXII, n. 75, agosto/2001.

RIBEIRO, Isabel C.; LISE, Mary A. T. Prova Brasil: descritores de avaliação de Matemática. Anais do XVI EREMATSUL. Porto Alegre, PUCRS, de 03 a 06 de junho de 2010. p. 330-341.

ROSE, Nikolas. El gobierno en las democracias liberales "avanzadas": del liberalismo al neoliberalismo. Archipiélago: cuadernos de crítica de la cultura, Barcelona: Archipiélago; Barcelona: Archipiélago, n. 29, p.25-40, verano. 1997.

SANTOS, Cleuza Iara Campello. InclusãoExclusão nas praticas pedagógicas dos professores que ensinam Matemática na Educação de Jovens e Adultos. Porto Alegre: Faculdade de Educação da UFRGS, 2008 (Dissertação de Mestrado).

SANTOS, Lucíola L. de C. P. História das disciplinas escolares: outras perspectivas de análise. In: CHAVES, Sandramara M.; TIBALLI, Elianda F. Anais do VII Encontro nacional de Didática e Práticas de Ensino: Conferências, mesas redondas e Simpósios. Vol. II, Goiânia 1994. pp 158-165.

SANTOS, S. A. Experiências narradas no ciberespaço: um olhar para as formas de se pensar e ser professora que ensina matemática. Porto Alegre, 2009. 123 f. Dissertação (Mestrado em Educação) - Universidade Federal do Rio Grande do Sul, Porto Alegre, 2009.

SOUSA, Sandra M. Z. Possíveis impactos das políticas de avaliação no currículo escolar. Cadernos de Pesquisa. São Paulo, n. 119. p. 175190. Jul/2003.

TRAVERSINI, Clarice Salete; BELLO, Samuel Edmundo López. O numerável, o mensurável e o auditável. Educação e realidade, Porto Alegre: UFRGS/FACED; Porto Alegre: UFRGS/FACED, v. 34, n. 2, p.135-152, mai/ago. 2009.

VEIGA-NETO, Alfredo. VEIGA-NETO, A. Governo ou governamento. Currículo sem Fronteiras, v.5, n.2, p.79-85, jul./dez. 2005. Disponível em: <www.curriculosemfronteiras.org/ vol5iss2articles/veiga-neto.pdf > Acesso em: 25 maio 2010.

Currículo e Interdisciplinaridade. In: MOREIRA, A. F. (org.) Currículo: questões atuais. 5ed. Campinas: Papirus, 1997. p. 59 -102.

A ordem das disciplinas: uma análise foucaultiana do movimento pela interdisciplinaridade. Porto Alegre, FACED/UFRGS, 1995.

XAVIER, Maria Luisa. Educação Básica resgatando espaços de humanização, civilização, aquisição e produção de Cultura na escola contemporânea. In: PEREIRA, N. M.; SCHÄFFER, N. O.; BELLO, S.L. Ler e escrever: compromisso no Ensino Médio. Porto Alegre: UFRGS editora - NIUE/UFRGS, 2008. p. 17-32. 


\section{Notas}

1 A Prova Brasil/Sistema de Avaliação da Educação Básica (SAEB), cujos resultados estão sendo divulgados pelo IDEB 2012, foi realizada em novembro de 2011 , de forma censitária na $4^{\mathrm{a}}$ série $/ 5^{\mathrm{o}}$ ano e na $8^{\mathrm{a}}$ séries $/ 9^{\circ}$ ano do Ensino Fundamental das escolas públicas das redes municipais e estaduais, e por amostragem no Ensino Médio, neste caso envolvendo apenas os alunos do $3^{\circ}$ ano que realizam o ENEM. c.f. http://www.educacao.rs.gov.br/pse/html/noticias_det.jsp?ID=9560 Acessado em 01 de outubro de 2012.

2 A meta brasileira de um IDEB nacional igual a 6,0 para 2022 tem como referência a qualidade dos sistemas em países da Organização para Cooperação e Desenvolvimento Econômico.

3 Nota de esclarecimento da Secretaria de Educação do RS (SEDUC), disponível em: http://www.educacao.rs.gov.br/pse/html/noticias_det.jsp?ID=9560 Acesso em 01 de novembro de 2012.

4 Essas visitas faziam parte do trabalho que era realizado como Professor de Prática de Ensino nos anos de 2007 a 2010.

5 Não é o intuito deste artigo desenvolver ou discutir uma noção de Prática. Para tanto, será tomado o sentido do termo dado por Miguel et al (2010), como sendo um conjunto articulado de ações já produzidas, significadas, realizadas, reconhecidas, legitimadas nos processos relacionais que envolve, parcial ou totalmente, os integrantes de uma comunidade social, política ou cultural. A rigor, as práticas não precisariam ser adjetivadas, pois as mesmas, seja em qualquer um desses âmbitos envolvem sempre uma produção simbólica. Contudo, permitir-me-ei adjetivar as mesmas de curriculares para situá-las no campo de forças que incidem na instituição escolar, tendo sua forma-objeto simbólico o Currículo.

6 Essas informações referem-se basicamente ao cálculo do índice para o ensino fundamental uma vez que para o Ensino Médio é utilizado o ENEM e a coleta de outros dados é feito por amostragem e não com um caráter censitário.

7 Segundo Veiga-Neto o termo Governamento, para falar de Governo, traduziria melhor aquilo que Michel Foucault na língua francesa denominaria de Governamentalité (Governamentalidade) para falar tanto das práticas de governo, como conjunto de saberes que institui uma racionalidade própria de Estado, quanto aos saberes necessários à maneira de se dirigir a conduta dos indivíduos ou de comunidades, instituições.

8 Utilizaremos o termo Governamento, ao invés de governo, para distingui-lo do sentido capturado e atribuído pela ciência política nos séculos XVII e XVIII.

9 Trabalho apresentado no 63 CIEAEM (Barcelona, Spain) e publicado no QUADERNI DI RICERCA IN DIDATTICA / Mathematics (QRDM). Quaderno n.22, Supplemento n.1 - PALERMO 2012, p. 114-118.

10 Para uma discussão sobre o termo ver também Bello (2012) no prelo.

11 A palavra estatística tem mais de um sentido: seu emprego no plural se refere às estatísticas descritivas como os dados colecionados, mas no singular se refere à teoria estatística e ao método pelo qual os dados são analisados. Assim, o termo podemos aplicá-lo tanto à interpretação de uma série de números como aos próprios números.

12 Essa desarticulação remete ao que em Traversini e Bello (2009) referimos como a auditabilidade de políticas e processos de avaliação, isto é, ao assumirem uma forma de auditoria por se tratarem de provas elaboradas por especialistas externos ao processo escolar desencadeado, as práticas pedagógicas tornam-se comparáveis umas às outras evidenciando assim seus resultados. Desta forma, a maquinaria avaliativa institui a evidência de práticas e estilos pedagógicos de sucesso, sugerindo fortemente a sua replicação independente de situação ou contexto de produção, advertência e destinação de recursos para as instituições que muito abaixo dos índices são vistas como problemáticas.

13 De janeiro a março de 1980, M. Foucault ofereceu no Collège de France o curso intitulado: Du gouvernement des vivants, traduzido para o português como o governo dos vivos. Um curso anterior a um outro intitulado o Governo de si e dos outros, oferecido de janeiro a março de 1983, para tratar da forma de constituição dos sujeitos pelos atos e práticas do dizer-verdadeiro. Neste texto preferimos traduzir o termo Vivants por viventes, por acreditarmos dar todavia um caráter mais provisório e em constituição à existência de um ser. O termo vivo pode nos remeter a um dito "ser vivo" e nos posicionar na grade de leitura das Ciências Biologias.

14 No que se refere à Matemática na Prova Brasil/SAEB e no ENEM, são elaboradas com base na Matriz de Referência de avaliação dessa disciplina para os Ensinos Fundamental e Médio, respectivamente. Essa Matriz é constituída a partir dos blocos de conteúdos propostos pelos PCN e pelos PCNEM e pelas habilidades e competências consideradas básicas para o final de cada um desses níveis de ensino. A relação conteúdos-habilidades/competências é expressa na matriz a partir de 37 descritores, em se tratando do ensino fundamental e 35 descritores para o Ensino Médio. 
15 Reconhecer que as imagens de uma figura construída por uma transformação homotética são semelhantes, identificando propriedades e/ou medidas que se modificam ou não se alteram. (D7 - Espaço e forma Matriz de referencia - EF)

16 Identificar a representação algébrica e/ou gráfica de uma função exponencial (D27 - Números e Operações - Matriz de referencia - EM)

17 Em 15 de agosto de 2012, o programa Conversas Cruzadas exibido pela TVCOM/Rio Grande do Sul do grupo RBS, trouxe como tema: RS tem os piores números da educação no sul do país, naquela ocasião insistia-se na contextualização e na aplicabilidade dos saberes escolares, bem como questionava-se a formação do professor para levar adiante este trabalho. http://mediacenter.clicrbs.com.br/tvcom-rsplayer/131/player/264251/conversas-cruzadas-15-08-2012-bloco-1/1/index.htm

\section{Sobre o autor:}

Samuel Edmundo Lopez Bello: Professor do Programa de Pós-graduação da Universidade Federal do Rio Grande do Sul. Porto Alegre. 